DOI: https://doi.org/10.24867/03KO03Cvejovic

\title{
ANALIZA PPP METODE KOD GNSS POZICIONIRANJA I DOSTUPNIH SOFTVERSKIH REŠENJA
}

\section{ANALYSIS OF PPP METHODS IN GNSS POSITIONING AND AVAILABLE SOFTWARE SOLUTIONS}

\section{Aleksandar Cvejović, Fakultet tehničkih nauka, Novi Sad}

\section{Oblast - GEODEZIJA I GEOMATIKA}

Kratak sadržaj - Precise Point Positioning pronalazi svoju primenu u satelitskom pozicioniranju $i$ obradi podatka dobijenih ovim putem. Odlikuje se visokom tačnošću i primenom kompleksnih algoritama za obradu podataka. Rad se zasniva na poređenju dostupnih softverskih rešenja za obradu podataka u PPP režimu.

Ključne reči: Precise Point Positioning, RTKLIB, gLAB, CSRS-PPP, GNSS.

Abstract - Precise Point Positioning finds its application in satellite positioning and processes data obtained through this way. It is characterized by high accuracy and application of complex data processing algorithms. The work is based on comparing available software solutions for data processing in PPP mode.

Ključne reči: Precise Point Positioning, RTKLIB, $g L A B$, CSRS-PPP, GNSS.

\section{UVOD}

Danas, prilikom korišćenja GNSS tehnologije, ukoliko želimo da postignemo rezultate visoke tačnosti potrebno je koristiti neku od mreža permanentnih stanica. Ovaj način pozicioniranja zahteva komunikaciju sa nekom od referentnih stanica koje se nalaze u području merenja. U poslednjih 15 godina razvijen je Precise Point Positioning (PPP) metod koji ne zahteva komunikaciju sa referentnim stanicama, već koristi podatke o korekcijam efemerida, časovnika, jonosfere i troposfere koje su dostupne na internetu.

Za PPP se može reći da predstavlja ekonomičniji metod pozicioniranja i obrade podatka merenja, pošto su podaci koje objavljuje Međunarodna GNSS služba dostupni na internetu i potpuno su besplatni. Posebno je koristan $u$ područjima sa nerazvijenom mrežom permanentnih stanica ili na području sa lošim internet prijemom.

Kako se PPP metodom može postići centimetarska tačnost, ovaj model zadovoljava potrebe geodetskog premera sa stanovišta tačnosti.

\section{GLOBAL NAVIGATION SATELITE SYSTEM}

Globalni navigacioni satelitski sistem (GNSS), koji pruža autonomno geoprostorno pozicioniranje sa globalnom pokrivenošću. GNSS omogućava prijemnicima detekciju njihove lokacije (longitude, latitude i altitude).

\section{NAPOMENA:}

Ovaj rad proistekao je iz master rada čiji mentor je bio dr Bulatović Vladimir, red.prof.
Globalna pokrivenost postignuta je konstalacijama od oko 30 satelita u srednjoj Zemljinoj orbiti u različitim orbitalnim ravnima. Aktuelni sistemi koriste orbitalne inklinacije od $>50^{\circ}$, te orbitalne periode oko 12 sati [1].

Globalni navigacioni satelitski sistem čine sledeći sistemi:

- Global Positioning System (GPS)

- GLONASS

- Galileo

- Compass

- DORIS

- IRNSS

- QZSS

\section{PRECISE POINT POSITIONING (PPP)}

Precise Point Positioning je metoda preciznog satelitskog pozicioniranja koja je razvijana u proteklih 15 godina. Ovaj pristup je nastao zbog dostupnosti preciznih GPS orbita i korekcija časovnika sa centimetarskom preciznošću. Primenom ovih korekcija mogu se značajno smanjiti greške satelitskih orbita i časovnika, koje predstavljaju dva najznačajnija izvora grešaka u GPS pozicioniranju. Kombinovanjem preciznih satelitskih efemerida i časovnika, sa dvofrekventnim prijemnikom (kako bi se otklonio uticaj jonosfere), PPP je u mogućnosti da postigne centimetarsku ili decimetarsku preciznost.

PPP se razlikuje od RTK (Real-Time Kinematic) po tome što ne zahteva komunikaciju sa nekom od referentih stanica, koja se nalazi na području merenja. Reč "precise" se koristi da istakne razliku od konvencijalnih tehnika pozicioniranja, koje koriste samo kodna ili fazna merenja kao glavne parametre za određivanje pozicije [2]. Ovakva tehnika pozicioniranja znatno smanjuje potrebe za održavanjem mreže permanentnih stanica, takođe omogućava izvođenje merenja u području sa nedovoljno izgrađenom infrastrukturom referentnih stanica.

Takođe PPP predstavlja apsolutno pozicioniranje umesto relativnog kao što je to slučaj kada se radi u režimu RTK. PPP metod pozicioniranja zahteva samo podatke o preciznim efemeridama i časovnicima satelita, izračunate od strane centra za obradu sa merenjima od referentinih stanica koje se nalaze rasprostranjene po celom svetu. Ovo čini PPP metodu značajnom alternativom RTK za područja koja nisu pokrivena referentnim stanicama, odnosno za područja gde nije moguće izvršiti merenja u RTK režimu pozicioniranja. 
Međutim PPP tehnika nije dovoljno razvijena kao RTK metoda i zahteva duže vreme opažanja kako bi se postigle maksimalne performanse. Takođe sistem PPP u realnom vremenu je još uvek u razvoju.

PPP metoda nudi značajne pogodnosti u poređenju sa tehnikom diferencijalnog pozicioniranja, a te prednosti su:

- PPP zahteva samo jedan GNSS prijemnik, a u blizini korisnika nije potrebno postojanje referentne stanice.

- Ovaj metod pozicioniranja pruža mnogo veću konzistentnost pozicioniranja u odnosu na diferencijalni pristup u kojima su rešenja dobijena u odnosu na neku referentnu stanicu.

- PPP smanjuje troškove rada i opreme, pojednostavljuje operativnu logistiku u radu na terenu, jer eliminiše zavisnost od bazne stanice.

Postizanje visoke tačnosti pozicioniranja je moguća primenom proizvoda koji su dostupni od strane Međunarodne GNSS službe(IGS) kao što su parametri (Slika 1): parametri zemljine rotacije, korekcije časovnika sa vremenskim intervalom od 30 sekundi, a takođe su dostupni podaci o orbitama satelita.

\begin{tabular}{|c|c|c|c|c|c|}
\hline & Type & Aceuracy & Delay & $\begin{array}{l}\text { Frequency of } \\
\text { update }\end{array}$ & Interval \\
\hline \multicolumn{6}{|c|}{ 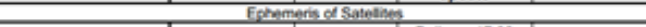 } \\
\hline & Rapis & $-2.5 \mathrm{~cm}$ & $17-41 \mathrm{~B}$ & $\begin{array}{l}\text { Dally on } 17: 00 \\
\text { UTCC }\end{array}$ & 15 minutes \\
\hline & Find & $-25 \mathrm{~cm}$ & $12 \cdot 18$ dans & Every Thursday & 15 minutes \\
\hline \multicolumn{6}{|c|}{ Coods of satolitides } \\
\hline & Rapid & $\begin{array}{l}-75 \mathrm{ps} \text { RMM } \\
-25 \mathrm{ps} S \mathrm{SDev}\end{array}$ & $17-41 \mathrm{~h}$ & $\begin{array}{l}\text { Daly on } 17.00 \\
\text { UTC }\end{array}$ & 5 minutes \\
\hline \multicolumn{2}{|r|}{ Find } & $\begin{array}{l}-75 \mathrm{ps} \mathrm{RMS} \\
-25 \mathrm{ps} \mathrm{SDev}\end{array}$ & \multirow{2}{*}{12.18 days } & Every Thursday & 30 seconds \\
\hline \multicolumn{5}{|c|}{ Parameters of Rousson of Earn } & \\
\hline \multirow{3}{*}{ Rapid } & $\begin{array}{l}\text { Movements d } \\
\text { polif }\end{array}$ & -40 pass & \multirow{3}{*}{$17-41 \mathrm{~B}$} & \multirow{3}{*}{$\begin{array}{l}\text { Daly on } 17.00 \\
\text { UTC }\end{array}$} & \multirow{3}{*}{$\begin{array}{l}\text { Daly on } 12: 00 \\
\text { UTC }\end{array}$} \\
\hline & $\begin{array}{l}\text { Change of } \\
\text { parameters of } \\
\text { tow movernent } \\
\text { of pole }\end{array}$ & -200 usastay & & & \\
\hline & Length of day & $-10 \mu \mathrm{a}$ & & & \\
\hline \multirow{3}{*}{ Fins } & Movemente of & -30 pas & \multirow{3}{*}{$11 \cdot 17$ days } & \multirow{3}{*}{ Every Thuradey } & \multirow{3}{*}{$\begin{array}{l}\text { Daily on } 12: 00 \\
\text { UTC }\end{array}$} \\
\hline & $\begin{array}{l}\text { Change of } \\
\text { parameters of } \\
\text { the movernent } \\
\text { of pole }\end{array}$ & -150 pasviday & & & \\
\hline & Length of day & $-10 \mu \mathrm{a}$ & & & \\
\hline
\end{tabular}

Slika 1. Parametri dostupni od strane IGS službe

Realizacija i dobijanje parametra, koji su cilj IGS-a, bio bi nemoguć bez 350 referentnih stanica za obzervaciju, kao i globalnih i regionalnih centara za analizu dobijenih podataka.

U slučaju merenja sprovedenih PPP tehnikom, koja ne zahteva komunikaciju sa referentnom mrežom, neophodna je primena preciznih proizvoda koji su dobijeni od strane IGS-a. U PPP tehnici uzeti su u obzir veliki broj korekcija i dodatnih podataka kako bi se postigla visoka tačnost pozicioniranja.

Pri razovoju softvera koji implementiraju PPP, mogu se koristiti specijalizovani softveri kao što su Bernese GPS Softver, EZSurv takođe postoje i open-source softveri RTKlib, gLAB. Alternativno rešenje može biti korišćenje online servisa koji vrše obradu u PPP režimu kao što su: magicGNSS, GNSS Analysis and Positioning (GAPS), Canadian Spatial Reference System Precise Point (CSRSPPP).

\section{STUDIJA SLUČAJA}

Zadatak ovog rada je da se ispitaju mogućnosti PPP metode pozicioniranja upotrebom dostupnih softverskih rešenja. Za obradu RINEX datoteka korišćeni su Open source softveri, kao i online sevisi za obradu GNSS podataka u PPP režimu pozicioniranja.
Prilikom procesiranja podataka korišćena su softverska rešenja koja su dostupna na internetu kao što su: RTKLIB, gLAB i CSRS-PPP online servis. Oblast istraživanja ovog rada jeste određivanje položaja tačaka primenom PPP metode pozicioniranja sa različitom dužinom opažanja, nakon čega je izvršeno poređenje dobijenih rezultata sa rezultatima dobijenim relativnim pozicioniranjem.

Test područje formirano je od 3 tačke na kojima se nalaze GNSS prijemnici. Kao rezultat opažanja dobijeni su RINEX 2.1 fajlovi, sa periodom opažanja od 24 sata. Tačke koje formiraju figuru se nalaze na teritoriji Vojvodine, odnosno u gradovima Zrenjanin, Subotica i Sombor

\subsection{RTKlib}

RTKlib je softverski paket otvorenog koda (open source) za standardno i precizno pozicioniranje za GNSS sisteme [3]. Prednosti RTKLIB-a su sledeće :

- Podržava algoritme za standarde i precizno pozicioniranje za GPS, GLONASS, Galileo, QZSS, BeiDou i SBAS satelitske sisteme.

- Podržava različite režime pozicioniranja za GNSS u realnom vremenu kao i za rad u naknadnoj obradi podataka.

- Podržava različite standarde formate i protokole za GNSS kao što su : RINEX 2.10, 2.11, 2.12, OBS/NAV/GNAV/HNAV/LNAV/QNAV, RINEX 3.00, 3.02 OBS/NAV, RINEX 3.02 CLK, RTCM, BINEX, ANTEX.

RTKLIB pruža rešenja kako u vidu tekstualne datodetke tako i grafički prikaz dobijenih rezultata (Slika 2).

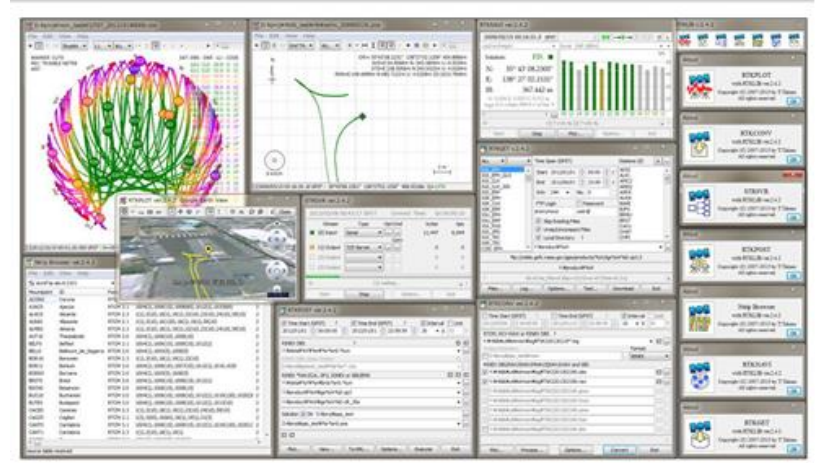

Slika 2. Prikaz Open Source softverskog rešenja RTKLIB

RTKLIB pruža mogućnost analize dobijenih podatak u režimu naknadne obrade podataka. U okviru RTKLIB-a izabere se RTKPOS režim.

Kao ulazni podaci u RTKPOST-u koriste se standardni RINEX formati 2.10, 2.11, 2.12, 3.00, 3.01, 3.02 kao fajlovi koji sadrže podatke o opažanjima, takođe se koriste i navigacioni podaci za (GPS, GLONASS, Galilleo, QZSS, BeiDou i SBAS).

$\mathrm{Na}$ osnovu ovih podataka računa se pozicija u zavisnosti od izabranog modela pozicioniranja (Single-Point, DGPS/DGNSS, Kinematika, Statika, PPP-Kinematika, PPP-Statika). 


\section{2. gLAB}

gLAB je interaktivni, obrazovni, višenamenski programski paket za obradu i analizu GNSS podataka. Prvo izdanje ovog softverskog paketa omogućilo je obradu samo GPS podataka. Sadašnje izdanje (Slika 3) je prošireno na SBAS i diferencijalno pozicioniranje (DGNSS). Takođe je u razvoju nova verzija ovog softverskog rešenja koja uključuje i buduće module, kao što je proširenje na Galilleo i GLONASS sisteme [4].

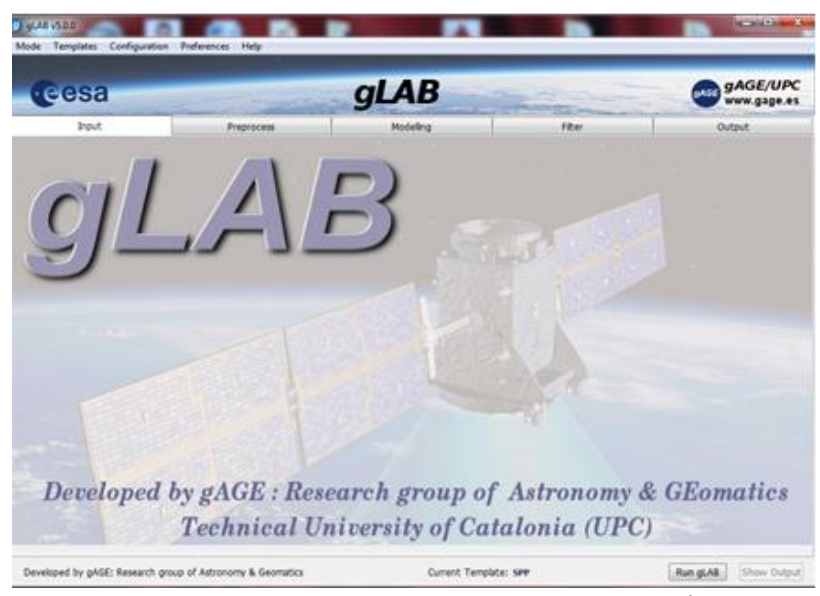

Slika 3. Prikaz Open Source softverskog rešenja $g L A B$

\subsection{CSRS-PPP}

Canadian Spatial Reference System (CSRS) je jedan od Online servisa (Slika 4) za procesiranje GNSS podataka, koji omogućava korisniku izračunavanje pozicije sa velikom preciznošću u naknadnoj obradi podataka [5].

Razvijen od strane Kanadskog geodetskog tima koji ima za cilj da definiše, održava i kontinuirano unapredi efikasan pristup Kanadskom prostornom referentnom sistemu, putem različitih geodetskih alata i proizvoda. Precizno pozicioniranje (širine, dužine i visine) je moguće ostvariti kroz tradicionalne metode premera, a sada je moguće to postići i pomoću sateltiskih tehnologija.

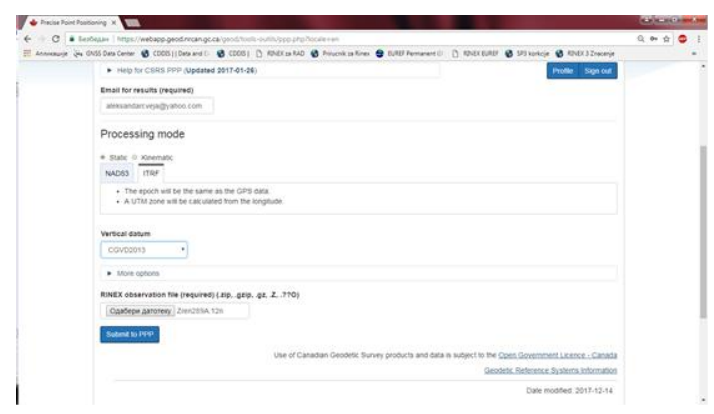

Slika 4.Prikaz CSRS-PPP Online Servisa

CSRS-PPP koristi GNSS precizne satelitske efemeride kako bi proračunao koordinate konstantne "apsolutne" tačnosti, bez obzira gde se prijemnik nalazi na Planeti i bez obzira na blizinu poznatih baznih stanica.

Korisnici mogu procesirati RINEX datoteke sa jednofrekventnih ili dvofrekventnih prijemnika koji rade u kinematičkom ili statičkom režimu. Ovaj server radi preko Inerenta i vraća procesirane podatke u kanadskom prostornom referentnom sistemu ili Međunarodnom terestričkom referentnom okviru (ITRF).

\subsection{Leica Geo Office}

Leica Geo Office je komercijalni softver namenjen za obradu i manipulaciju goedetskih podataka dobijenih putem totalnih stanica, nivelira ili GPS prijemnika. U ovom softverskom rešenju izvršeno je procesiranje po metodi relativnog pozicioniranja, pri čemu su dobijene komponente baznih vektora između izabranih tačaka. Takođe je izvršena kontrola kvaliteta izvršenog poziconiranja primenom testa nezatvaranja poligona. Sračunate su dužine vektora između stanica koje su uzete kao tačne vrednosti u diskusiji dobijenih rezultata.

\section{ANALIZA DOBIJENIH REZULTATA}

Nakon obrade podataka potrebno je za područje od interesa, odnosno izabranu metodu pozicioniranja, analizirati dobijene rezultate. Analiza se vrši na osnovu izračunatih dužina između stanica ( Zrenjanin, Sombor, Subotica). Dužine se računaju na osnovu koordinatnih razlika između stanica, dobijenih primenom PPP metode pozicioniranja u izabranim softverskim rešenjima. Sračunate dužine se porede sa dužinama koje su dobijene procesiranjem baznih vektora (Tabela 1) u softveru Leica Geo Office. Dužine baznih vektora su usvojene kao tačne vrednosti.

\begin{tabular}{|ccccc|}
\hline |Somor-Subotica| & 56714.9313 & {$[\mathrm{~m}]$} & 56.7149313 & {$[\mathrm{~km}]$} \\
|Subotica-Zrenjanin| & 97235.7065 & {$[\mathrm{~m}]$} & 97.2357065 & {$[\mathrm{~km}]$} \\
|Zrenjanin-Sombor| & 107451.5169 & {$[\mathrm{~m}]$} & 107.4515169 & {$[\mathrm{~km}]$} \\
\hline
\end{tabular}

Tabela 1.Dužine sračunate u LGO-u

Kao rešenje proceseiranja u softverskom rešenju RTKLIB se dobija tekstualni fajl sa koordinatama za svaku sekundu pozicioniraja

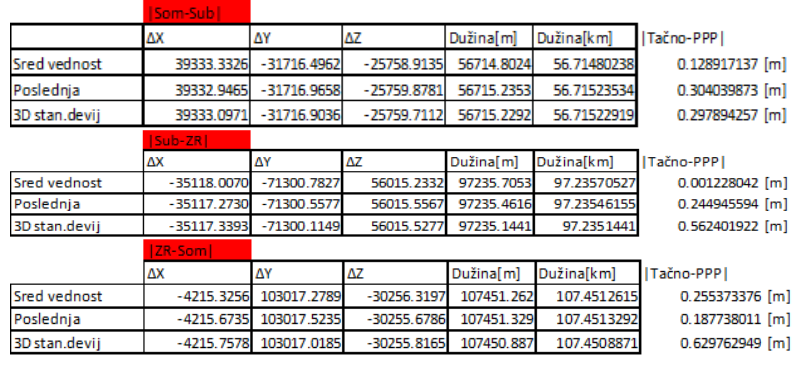

Razlika između dužina, sračunatih u softverskom rešenju RTKLIB, između stanica i dužina koje su usvojene kao tačne vrednosti pokazuje da se u ovom slučaju PPP metodom postiže dectimetarska tačnost. Može se videti da razlika između stanica Subotica - Zrenjanin iznosi par milimetara, dok je razlika kod ostalih nekoliko desetina centimetra. Na tačnost određivanja koordinata može uticati kvalitet korišćenih proizvoda za stelitske efemeride i časovnike.

Kao rezultat procesiranja u softverskom rešenju gLAB dobija se tekstualni fajl sa spiskom koordinata.

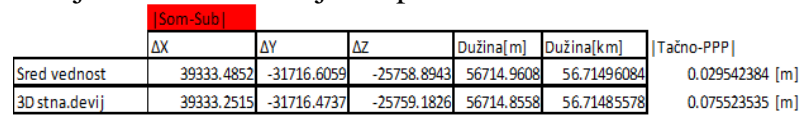




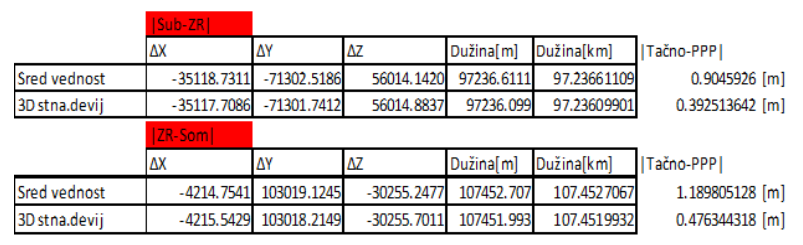

Razlika između dužina, sračunatih u softverskom rešenju gLAB između stanica, i dužina koje su usvojene kao tačne vrednosti pokazuje da se i u ovom slučaju PPP metodom postiže decimetarska tačnost pozicioniranja. Ipak može se videti da je između stanica Sombor i Subotica postignuta tačnost od $2 \mathrm{~cm}$ u odnosu na usvojenu vrednost.

Kod online servisa CSRS-PPP kao rezultat se dobije tekstualni fajl koji sadrši tabelarne i grafičke rezultate pozicioniranja. Koordinate tačaka kao rezultat pozicioniranja date su u obliku geografskih koordinata, koje su za potrebe računanja transformisane $u$ pravougle koordinate.

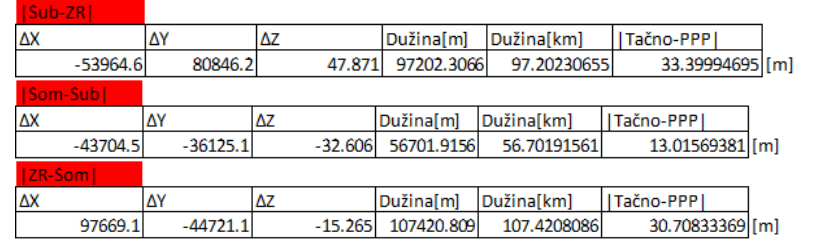

Razlika između dužina, sračunatih u online servisu CSRSPPP između stanica, i dužina koje su usvojene kao tačne vrednosti pokazuje da se u ovom slučaju PPP metodom ne postiže zadovoljavajuća tačnost za potrebe geodetskog premera.

Razlika iznosi preko 15 metara, a za razliku od predhodnih softvera, kod online servisa ne postoji mogućnost učitavanja preciznih proizvoda (satelitskih efemerida, časovnika).

\section{ZAKLJUČAK}

Osnovna ideja ovog master rada je da prikaže prednosti obrade podataka dobijenih primenom GNSS tehnologije, u PPP režimu. Jedna od glavnih prednosti ovog načina pozicioniranja je taj što ne zahteva komunikaciju sa nekom od referentnih stanica, a prilikom pozicioniranja zahteva upotrebu samo jednog dvofrekventnog prijemnika. Što dovodi do značajne uštede finansijkih sredstava, kao i uštedu u pogledu potrebne opreme za izvođenje merenja. Obrada podataka za potrebe ovog rada je vršena u softverskim paketima RTKLIB i gLAB, kao i online servisu CSRS-PPP.

Obrada se može vršiti u više režima i primenom različitih algoritama za obradu i rešavanje različitih problema obrade. Prilikom relativnog pozicioniranja potrebno je pored Rovera imati i Baznu stanicu ili Rover mora biti povezan na neku od mreža permanentinih stanica, što predstavlja dodatne finansiske troškove.

Precise Point Positioning (PPP) predstavlja brz i efikasan metod obrade podataka dobijenih GNSS merenjima.

Prvi deo master rada daje neka teorijska saznanja o GNSS sistemu, GPS konstalaciji satelita, njegovim segmentima kao i greškama koji utiču na proces merenja. Prikazana su i teoretski objašnjena korištena softverska rešenja, njihove prednosti i mane.
Drugi deo se odnosi na samu studiju slučaja. Studija slučaja se odnosi na prikaz obrade podataka u PPP režimu.

Naime, procesiranje je vršeno, kako je već rečeno u RTKLIB, gLAB i CSRS-PPP softverskim rešenjima, sa dodatnim grafičkim i tabelarnim prikazima radi lakšeg pregleda u konkretnom slučaju.

Samo jedan od softverskih rešenja ne daje zadovoljavajuće rezultate u pogledu tačnosti rezultata procesiranja, odnosno kod online servisa nije moguće dodatno učitati fajlove sa korekcijama već servis koristi korekcije koje su mu dostupne u bazi.

Stoga se koriste kompleksniji algoritmi za odbradu i otklanjanje grešaka u rezultatima merenja. RTKLIB i gLAB softverska rešenja pružaju zadovoljavajuće rezultate.

\section{LITERATURA}

[1]Dragan Blagojević (2007). Satelitska geodezija (Uvod u NAVSTAR GPS).

[2] Yang Gao (2006). GNSS Solutions: Precise Point Positoning and Its Challenges, from

http://insidegnss.com/wpcontent/uploads/2018/01/NovDec06GNSSSolutions.pdf .

[3] T.TAKASU (2009). RTKLIB ver.2.4.2 Manual.

[4] GNSS - lab tool,software User manual(gAGE). Retrieved 2018, from http://www.gage.upc.edu/sites/default/files/gLAB/gLAB $\underline{\text { SUM.pdf }}$

[5] CSRS - PPP User's Guide(n.d). Retrieved 2018, from https://www.nrcan.gc.ca/earthsciences/geomatics/geodetic -reference-systems/tools-applications/10925

\section{Kratka biografija:}

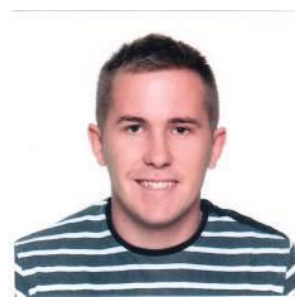

Aleksandar Cvejović rođen je u Kruševcu 1992. godine. Završava srednju ekonomsku skolu 2011. godine u Brusu smer ekonomski tehničar. Fakultet tehničkih nauka upisuje 2011. godine, smer Geodezija i geomatika. U Oktobru 2015. godine završava osnovne akademske studeje, sa završnim radom iz oplasti GPS tehnologije. 